\title{
Studi Performa Video Streaming pada Jaringan Kampus Unsrat
}

\author{
Arie S. M. Lumenta ${ }^{1}$ \\ ${ }^{1}$ Program Studi Teknik Elektro, F-TEKNIK, UNSRAT Manado, arie.lumenta@unsrat.ac.id
}

\begin{abstract}
Abstrak
Video streaming dapat digunakan untuk proses belajar mengajar di kampus. Dosen dapat mendistribusikan materi kuliah berupa file video kepada mahasiswa. Jaringan komputer kampus Unsrat yang selama ini hanya digunakan untuk akses internet dan sistem informasi terpadu kampus akan diberdayakan juga untuk membroadcast video. Untuk studi performa dibuat server komputer tempat file video yang akan dibroadcast di jaringan kampus. Komputer yang digunakan sebagai server sengaja diambil komputer lama yang sudah tidak digunakan untuk menunjukkan bahwa kebutuhan minimum sistem komputer untuk server video tidak terlalu berat. Hasil pengujian menunjukkan bahwa penggunaan bandwitdth untuk streaming relatif kecil dan tidak mengganggu performa jaringan secara keseluruhan.
\end{abstract}

Kata kunci: Video streaming, kompresi H.264

\section{Study of Video Streaming Performance on Campus Unsrat Network}

\begin{abstract}
Video streaming can be used for teaching and learning on campus. Lecturers can distribute course material to students in the form of video files. Unsrat computer network which is only used for Internet access and an integrated information system for the campus will be empowered also broadcasts a video. To study the performance created a computer server that will dibroadcast video files on the campus network. Computers are used as a server accidentally taken an old computer that has not been used to show that the minimum requirements for the computer system video server is not too heavy. The results show that the use of bandwitdth for streaming relatively small and do not interfere with the performance of the overall network.
\end{abstract}

Keywords: Video streaming, H.264 compression

\section{Pendahuluan}

Video streaming dapat diterapkan dalam proses belajar mengajar di perguruan tinggi. Dengan adanya video streaming materi kuliah yang disampaikan oleh dosen dapat diakses oleh mahasiswa yang mengininginkan materi kuliah tersebut. Selaini itu, materi kuliah tersebut dapat disimpan di komputer server untuk selanjutnya dapat diakses kapan saja.

Universitas Sam Ratulangi memiliki infrastruktur jaringan yang mengubungkan kantor pusat dengan seluruh fakultas dan lembaga serta unit kerja yang ada di lingkungan Unsrat. Jaringan tersebut digunakan civitas akademika untuk mengakses internet dari dalam lingkungan kampus. Disamping itu juga digunakan untuk mengakses sistem informasi terpadu kampus.

Untuk lebih memberdayakan infrastruktur jaringan kampus yang telah tersedia, maka direncanakan untuk menyediakan layanan server video streaming yang akan digunakan untuk membroadcast video kuliah yang sudah disiapkan oleh dosen.

Tulisan ini akan membahas studi awal persiapan penyediaan server video streaming di lingkungan kampus Unsrat. Studi dimaksud adalah untuk melihat performa videoa streaming jika dilewatkan di jaringan kampus.

\section{Metodologi}

Untuk melakukan studi performa videoa streaming, pertama-tama dibuat terlebih dahulu web server yang akan menjadi sarana untuk membroadcast video dalam jaringan. Ada dua web server video streaming yang dibuat. Dua komputer yang digunakan untuk web server ini sengaja diambil 
dari komputer lama yang sudah tidak digunakan yakni komputer dengan processor Pentium 43.00 $\mathrm{GHz}$ dan RAM $512 \mathrm{MB}$. Hal ini bertujuan untuk menunjukkan bahwa komputer lama sekalipun dapat dimanfaatkan dan digunakan untuk menempatkan file video.

Topologi dan konfigurasi jaringan yang digunakan untuk simulasi awal sebelum menggunakan jaringan kampus adalah seperti pada gambar.

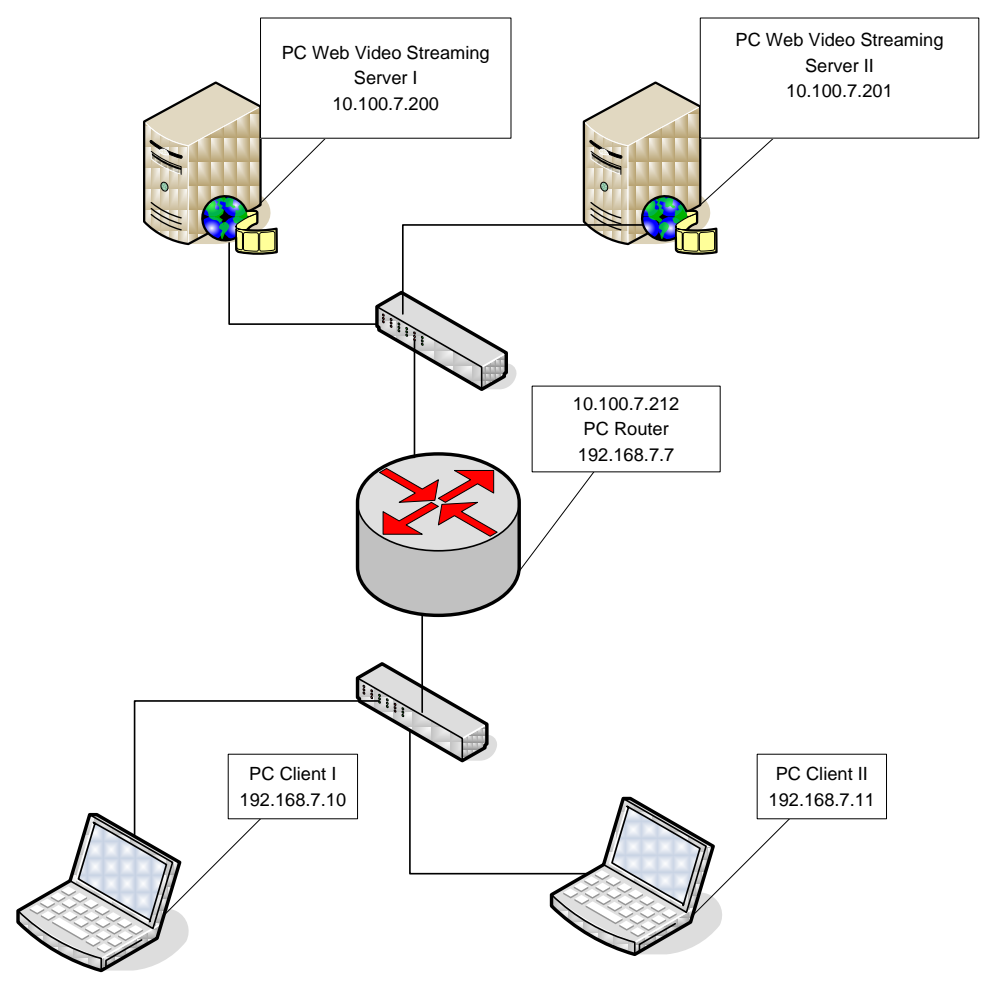

Gambar 1. Topologi awal studi

PC Web Video streaming menggunakan sistem operasi Linux Ubuntu dan aplikasi Apache Server, PHP dan MySQL. Untuk memudahkan dalam pembuatan aplikasi web digunakan Joomla. Untuk kompresi video digunakan aplikasi ffmpeg. Sedangkan untuk aplikasi streaming di server dan untuk menampilkan video streaming di client digunakan aplikasi $v l c$.

Pada eksperimen digunakan, ada dua file video yang digunakan, yang pertama adalah file avi dengan ukuran file $84,5 \mathrm{Mb}$ berdurasi 7 menit 35 detik format kompresi video xvid (H.263) dengan resolusi 720x296, frame rate 23,98fps, bitrate $913 \mathrm{kbps}$, format kompresi audio ac 3 dengan bitrate $640 \mathrm{kbps}$ dan frekuensi $48000 \mathrm{~Hz}$. File tersebut kemudian diubah ukuran resolusinya menjadi 480x320 yang merupakan resolusi standar untuk video streaming, codec audio aac, bitrate audio 96kbps dan standar frame 25fps (PAL) dan 30fps (NTSC) dengan nilai bitrate yang berubah-ubah yaitu 400, 600, 800 dan 1000kbps.

File kedua adalah file avi dengan ukuran file $23,9 \mathrm{Mb}$ berdurasi 53 detik format kompresi video divx (H.263) dengan resolusi 1920x816, frame rate 23,98fps, bitrate $3538 \mathrm{kbps}$, format kompresi audio mp3 dengan bitrate 160kbps dan frekuensi $48000 \mathrm{~Hz}$, yang kemudian diubah ukuran resolusinya menjadi 480x320 yang merupakan resolusi standar untuk video streaming, codec audio aac, bitrate audio 96kbps dan standar frame 25fps (PAL) dan 30fps (NTSC) dengan nilai bitrate yang berubah-ubah yaitu 400, 600, 800 dan 1000kbps.

Dua file untuk simulasi dan studi performa video streaming akan dikompress terlebih dahulu ke format standar kompresi H.264, dengam format .mp4, untuk mendapatkan file dengan ukuran yang lebih kecil tanpa mengorbankan kualitas yang terlalu banyak. Tujuannya adalah untuk efisiensi bandwidth. 
Selanjutnya setelah eksperimen pada toplogi jaringan awal berhasil dilakukan, eksperimen berikutnya dilakukan pada jaringan kampus yang memiliki topologi dan konfigurasi jaringan seperti pada gambar 2 .

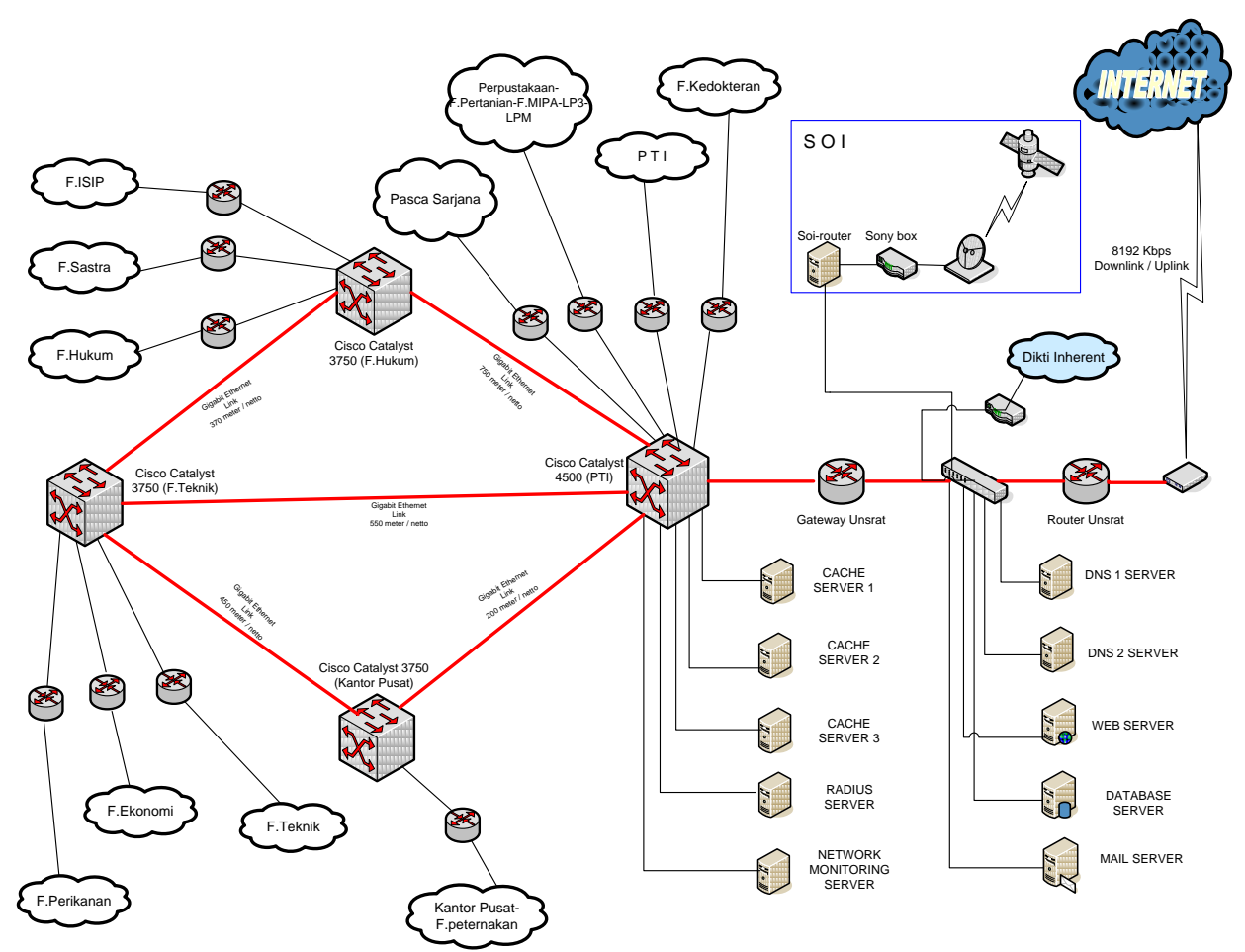

Gambar 2. Topologi Jaringan Kampus

Pada jaringan kampus ditambahkan sebuah web server dengan menggunakan alamat ip 192.168.0.127 dan sebuah streaming server dengan alamat ip 192.168.0.128 pada gateway Unsrat.

\section{Hasil dan Pembahasan} tabel 2.

Kompresi pada kedua file sampel diperoleh hasil sebagai berikut seperti pada tabel 1 dan

Tabel 1. Hasil Kompresi File ukuran 84,5Mb dengan frame rate $25 \mathrm{fps}$

\begin{tabular}{|c|c|c|c|c|}
\hline $\begin{array}{c}\text { File Input } \\
(\mathrm{Mb})\end{array}$ & $\begin{array}{c}\text { Bitrate Kompresi } \\
(\text { Kbps })\end{array}$ & $\begin{array}{c}\text { Frame rate } \\
(\mathrm{fps})\end{array}$ & $\begin{array}{c}\text { Lama } \\
\text { Kompresi }\end{array}$ & $\begin{array}{c}\text { File Output } \\
(\mathrm{Mb})\end{array}$ \\
\hline 84,5 & 400 & 25 & $5 \mathrm{~m} 30 \mathrm{~s}$ & 31,7 \\
\hline 84,5 & 600 & 25 & $6 \mathrm{~m}$ & 42,1 \\
\hline 84,5 & 800 & 25 & $6 \mathrm{~m} 30 \mathrm{~s}$ & 52,5 \\
\hline 84,5 & 1000 & 25 & $6 \mathrm{~m} 30 \mathrm{~s}$ & 62,8 \\
\hline
\end{tabular}

Tabel 2. Hasil Kompresi File ukuran 84,5Mb dengan frame rate $30 \mathrm{fps}$

\begin{tabular}{|c|c|c|c|c|}
\hline $\begin{array}{c}\text { File Input } \\
(\mathrm{Mb})\end{array}$ & $\begin{array}{c}\text { Bitrate Kompresi } \\
(\mathrm{Kbps})\end{array}$ & $\begin{array}{c}\text { Frame rate } \\
(\mathrm{fps})\end{array}$ & $\begin{array}{c}\text { Lama } \\
\text { Kompresi }\end{array}$ & $\begin{array}{c}\text { File Output } \\
(\mathrm{Mb})\end{array}$ \\
\hline 84,5 & 400 & 30 & $5 \mathrm{~m} 30 \mathrm{~s}$ & 28,3 \\
\hline 84,5 & 600 & 30 & $5 \mathrm{~m} 45 \mathrm{~s}$ & 37,0 \\
\hline 84,5 & 800 & 30 & $5 \mathrm{~m} 55 \mathrm{~s}$ & 45,6 \\
\hline 84,5 & 1000 & 30 & $6 \mathrm{~m} 18 \mathrm{~s}$ & 54,2 \\
\hline
\end{tabular}

Grafik perbandingan kompresi dengan frame rate berbeda seperti ditunjukkan pada gambar 3 . 


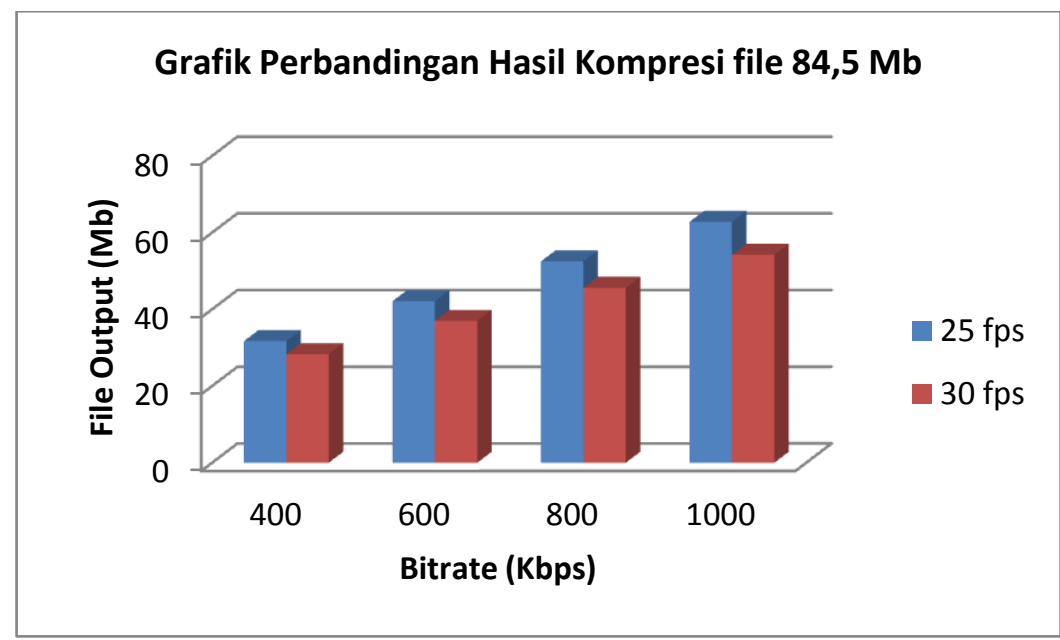

Gambar 3. Grafik perbandingan kompresi file $84,5 \mathrm{Mb}$

Dari grafik terlihat bahwa pada frame rate 30 fps ukuran file yang dihasilkan lebih kecil dibandingkan dengan pada frame rate 25 fps.

Untuk file dengan ukuran $29,3 \mathrm{Mb}$ hasil kompresinya adalah sebagai berikut seperti ditunjukkan pada tabel 3 dan tabel 4.

Tabel 3. Hasil Kompresi File ukuran 23,9Mb dengan frame rate $25 \mathrm{fps}$

\begin{tabular}{|c|c|c|c|c|}
\hline $\begin{array}{c}\text { File Input } \\
(\mathrm{Mb})\end{array}$ & $\begin{array}{c}\text { Bitrate Kompresi } \\
(\mathrm{Kbps})\end{array}$ & $\begin{array}{c}\text { Frame rate } \\
(\mathrm{fps})\end{array}$ & $\begin{array}{c}\text { Lama } \\
\text { Kompresi }\end{array}$ & $\begin{array}{c}\text { File Output } \\
(\mathrm{Mb})\end{array}$ \\
\hline 23,9 & 400 & 25 & $30 \mathrm{~s}$ & 3,4 \\
\hline 23,9 & 500 & 25 & $31 \mathrm{~s}$ & 4 \\
\hline 23,9 & 600 & 25 & $31 \mathrm{~s}$ & 4,4 \\
\hline 23,9 & 700 & 25 & $31 \mathrm{~s}$ & 4,7 \\
\hline
\end{tabular}

Tabel 4. Hasil Kompresi File ukuran 23,9Mb dengan frame rate $30 \mathrm{fps}$

\begin{tabular}{|c|c|c|c|c|}
\hline $\begin{array}{c}\text { File Input } \\
(\mathrm{Mb})\end{array}$ & $\begin{array}{c}\text { Bitrate Kompresi } \\
(\mathrm{Kbps})\end{array}$ & $\begin{array}{c}\text { Frame rate } \\
(\mathrm{fps})\end{array}$ & $\begin{array}{c}\text { Lama } \\
\text { Kompresi }\end{array}$ & $\begin{array}{c}\text { File Output } \\
(\mathrm{Mb})\end{array}$ \\
\hline 23,9 & 400 & 30 & $25 \mathrm{~s}$ & 3,2 \\
\hline 23,9 & 500 & 30 & $26 \mathrm{~s}$ & 3,5 \\
\hline 23,9 & 600 & 30 & $26 \mathrm{~s}$ & 3,9 \\
\hline 23,9 & 700 & 30 & $26 \mathrm{~s}$ & 4,2 \\
\hline
\end{tabular}

Dari kedua hasil tersebut, grafik perbandingan hasil kompresinya adalah seperti yang ditunjukkan pada gambar 4.

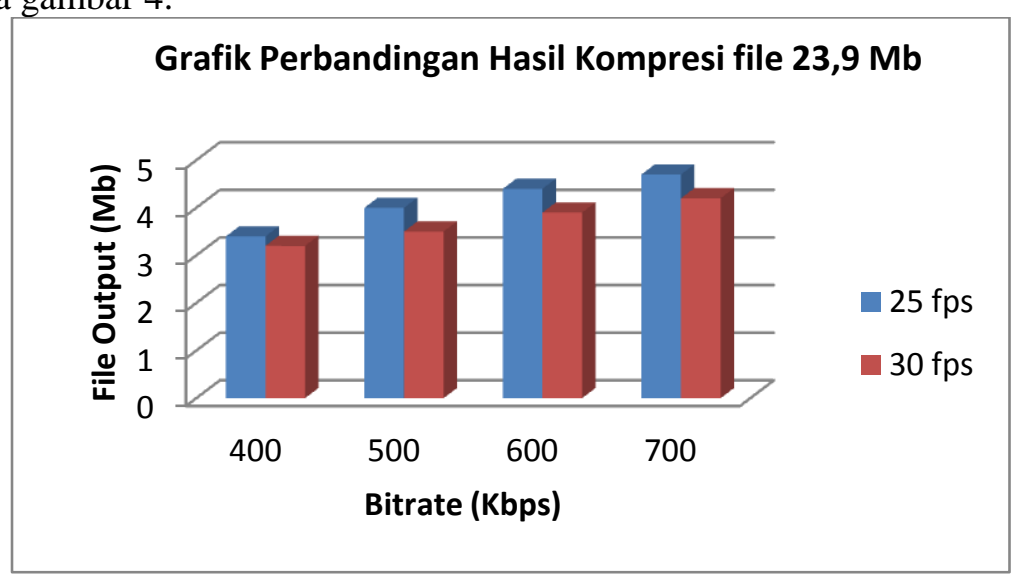

Gambar 3. Grafik perbandingan kompresi file 23,9Mb 
Hasil pada gambar 4 menunjukkan hal yang serupa dengan file pertama yang berukuran $84,5 \mathrm{Mb}$. Selanjutnya akan dilihat performa video streaming dalam jaringan dengan mengukur penggunaan bandwidth yang digunakan oleh kedua file yang telah dikompres dalam proses upload maupun streaming di jaringan.

Untuk file yang berukuran $84,5 \mathrm{Mb}$, hasilnya dapat dilihat pada gambar 4 dan gambar 5 .

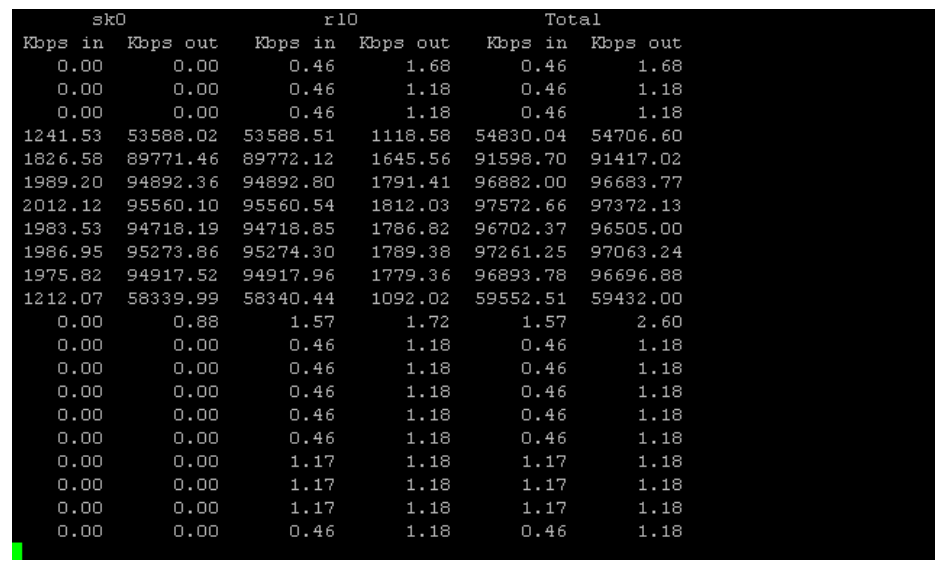

Gambar 4. Proses upload file yang berukuran 84,5Mb.

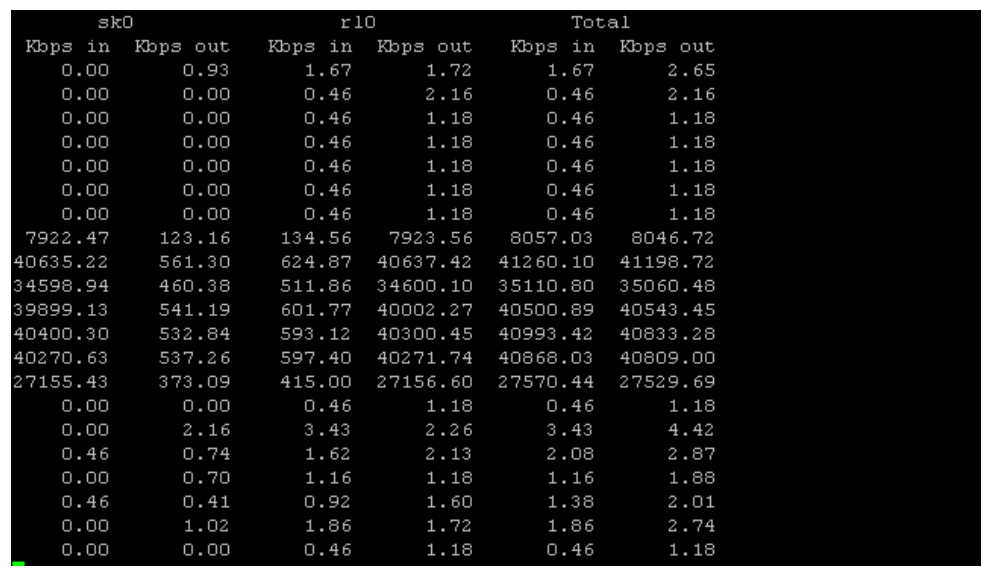

Gambar 5. Proses streaming file yang berukuran $84,5 \mathrm{Mb}$.

Dari gambar 4 dan 5, terlihat bahwa bandwidth yang dibutuhkan sekitar 41000 Kbps.

Untuk file dengan ukuran $23,9 \mathrm{Mb}$, penggunaan bandwidth di dalam jaringan adalah seperti yang ditunjukkan pada gambar 6 dan gambar 7 .

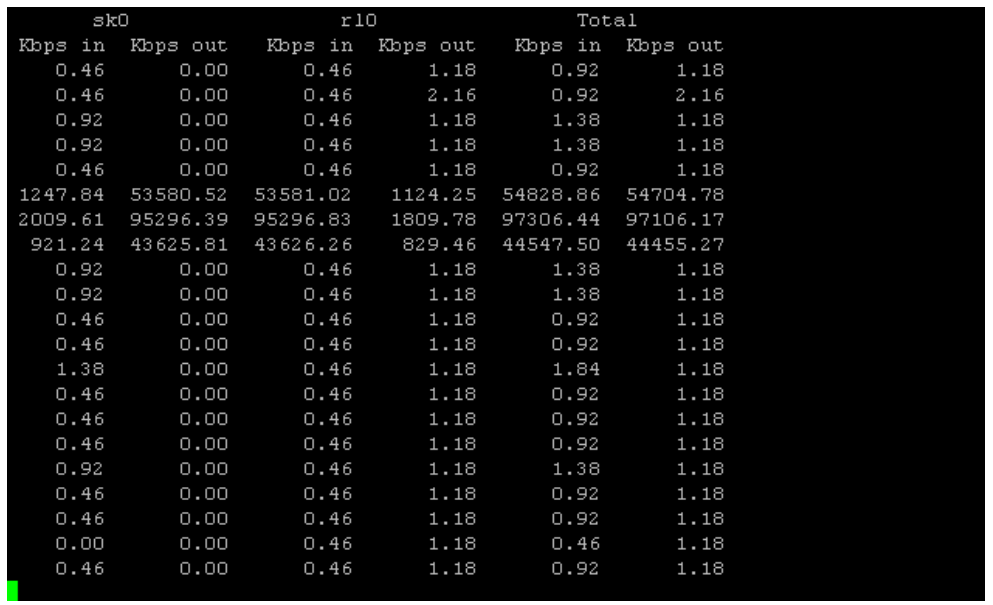

Gambar 6. Proses upload file yang berukuran 23,9Mb. 


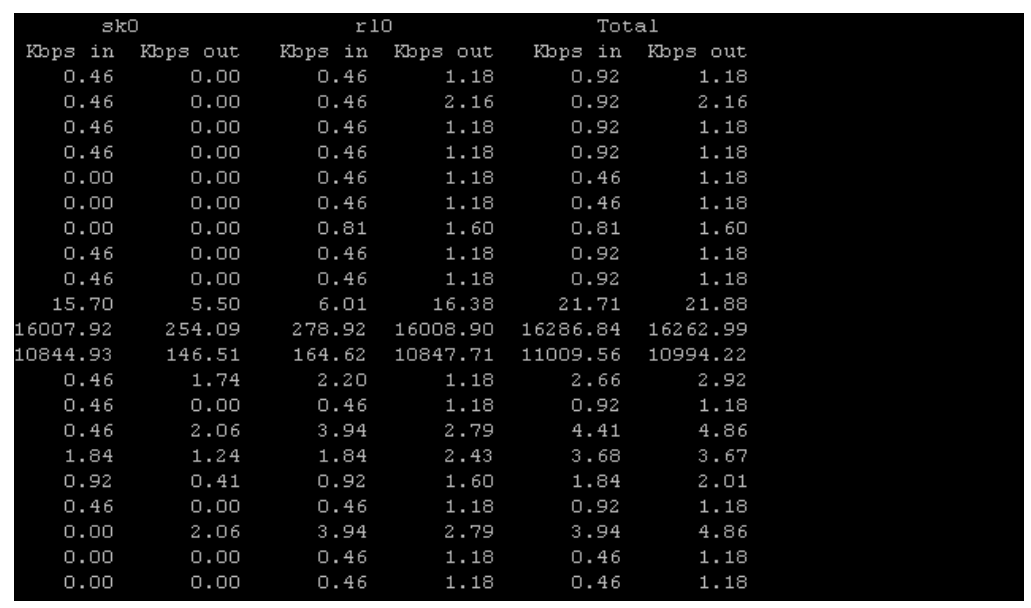

Gambar 7. Proses streaming file yang berukuran 23,9Mb.

Dari hasil diatas terlihat bahwa penggunaan bandwidth dalam jaringan untuk file dengan ukuran 23,9Mb adalah sekitar 16000 Kbps.

Perbandingan penggunaan bandwidth kedua file tersebut dapat dilihat pada gambar 8 berikut.

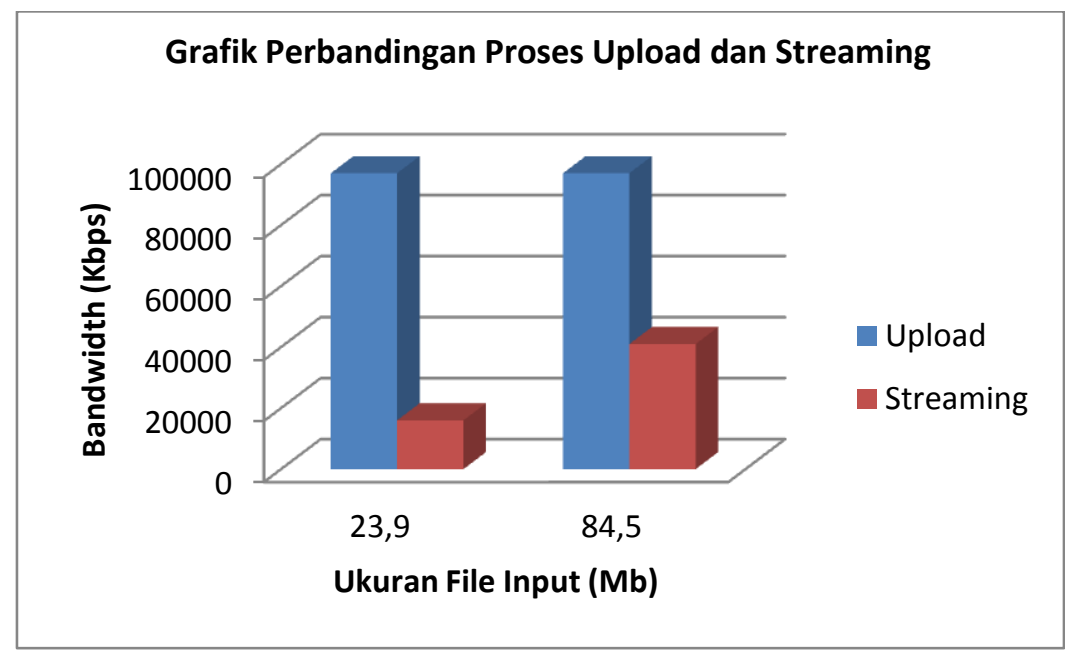

Gambar 8. Grafik Perbandingan proses Upload dan Streaming.

\section{Penutup}

Penggunaan kompresi H.264 menunjukkan bahwa ukuran file menjadi lebih kecil tanpa mengorbankan kualitas video. Selanjutnya file hasil kompres H.264 yang dilewatkan di jaringan hanya menggunakan bandwidth yang relatif kecil dan secara keseluruhan tidak mengganggu performa jaringan.

\section{Daftar Pustaka}

[1] Dalheimer, M.K dan Welsh, M. 2005. Running Linux, 5th Edition. O'Reilly Media, Inc.

[2] Groth, D dan Skandier, T. 2005. Network ${ }^{T M}$ Study Guide, Fourth Edition. Sybex Inc. Alameda.

[3] http://www.ffmpeg.org/

[4] http://www.videolan.org/vlc/ 